\title{
Knowledge Management for Plant Shutdown in Collaborative Virtual Reality
}

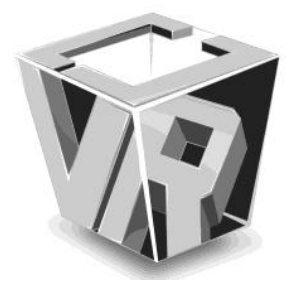

\author{
Andrew Strelzoff ${ }^{1}$ and Tulio Sulbaran ${ }^{2}$ \\ ${ }^{1}$ The University of Southern Mississippi, School of Computing \\ ${ }^{2}$ The University of Southern Mississippi, School of Construction
}

\begin{abstract}
Oil refineries run nearly continuously twenty-four hours a day. The process of doing routine maintenance, adding or rebuilding refinery process rigs and powering down is referred to as "shutdown". Refineries are extraordinarily complicated and shutdowns are therefore very problematic and expensive. Poorly planned or executed shutdown can result in loss of life and millions of dollars of lost productivity. There is also an important collaborative and knowledge management aspect in that all shutdowns involve many people and are executed by temporary contractors who are often unfamiliar with the details of the plant they are shutting down.

Commonly, text and two dimensional drawings are used in preparation for a plant shutdown and exchanging of information. However, with the advent of new technologies it is now possible to also exchange knowledge three dimensionally including multimedia and dynamic files. One technology that enhances the knowledge exchanging and management is Collaborative Virtual Reality Environment (CVRE). CVREs allow users to interact with a computer-simulated environment, be it a real or imagined while using the Internet to collaborate and interact with possibly many other users that may be spread over large distances.

Virtual Reality has been widely applied in various forms to plant shutdown planning but the knowledge management aspect of the process is not being addressed by these technologies. In this paper we describe the early use and underlying details of an innovation implantation of a Collaborative Virtual Whiteboard (CVW) inside of an CVRE for knowledge management during the plant shutdown planning.
\end{abstract}

Index Terms-Virtual Reality Application, Collaboration, Multimedia Information Systems, Knowledge Management

\section{INTRODUCTION}

Knowledge management is the systematic process of finding, selecting, organizing and presenting information in a manner that improves the understanding of a person on a given topic. The management of knowledge helps an organization to take advantage of its experience and know-how (insights) [1]. Such experiences and insights comprise knowledge, either embodied in individuals or embedded in organizational processes or practice. An established discipline since 1995, knowledge management includes courses taught in the fields of business administration, information systems, management, and library

Manuscript received on December 2008

E-Mail: Andrew.Strelzoff@usm.edu and information sciences [2]. Many large companies and non-profit organizations have resources dedicated to internal knowledge management efforts, often as a part of their 'Business Strategy', 'Information Technology', or 'Human Resource Management' departments [3]. Knowledge management efforts typically focus on organizational objectives such as improved performance, competitive advantage, innovation, the sharing of lessons learned, and continuous improvement of the organization. Knowledge management efforts can help individuals and groups to share valuable organizational insights, to reduce redundant work, to avoid reinventing the wheel per se, to reduce training time for new employees, to retain intellectual capital as employees' turnover in an organization, and to adapt to changing environments and markets $[4,5]$.

Knowledge is critically important during a plant shutdown when there is an increased demand for resources, a long list of planned work over a limited period of time, work plans are modified, and special equipment is leased to accomplish the additional work [6]. An example of plant shutdown planning from the literature is shown in Fig. 1.

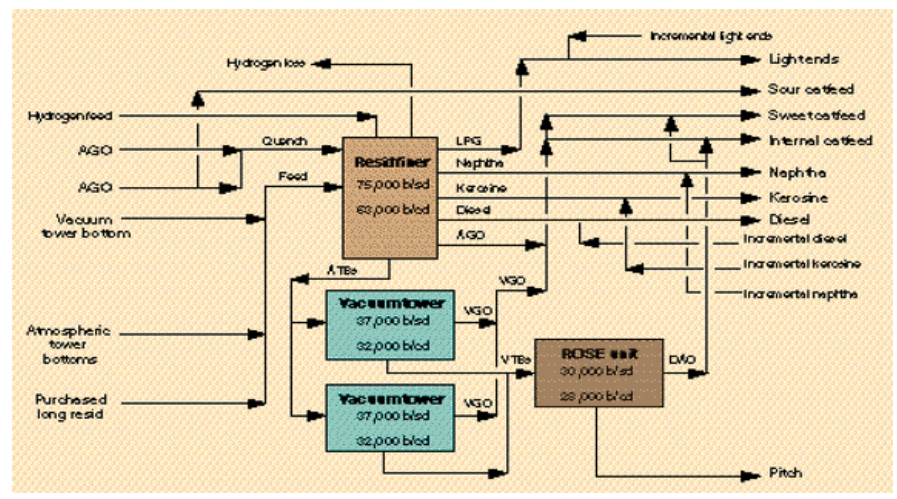

Fig. 1. Example of refinery plant shutdown planning [Rhodes A. 1995]

The amount of work needed is defined when a work list is created including planning, programming, implementation and management of the plant shutdown. During the preparation of this work list and during the plant shutdown it is very important that the experiences and insights embodied in individuals and in the organization including processes and practice are used to their best advantage. Because each plant shutdown is unique to the plant, and at the same time uses similar implementation processes to meet the demands of today's competitive environment. These similarities allow companies to used 
expertise of individuals that are physically located hundreds of miles from the plant, which add additional logistical challenges to the knowledge management during the plant shutdown. Virtual Reality has been widely applied in various forms to plant shutdown planning $[7,8,9]$ but the knowledge management aspect of the process is not being addressed by these technologies. Thus, the goal of this paper is to describe the integration of two currently available technologies: Electronic Whiteboards and Collaborative Virtual Reality Environment (CVRE) to support the management and exchange of knowledge among the stakeholders of a Plant Shutdown that could be physically located around the world.

\section{KNOWLEDGE MANAGEMENT IN COLLABORATIVE VIRTUAL REALITY}

Virtual Reality has existed for many years and it is a technology that allows a user to interact with a computer-simulated environment, be it a real or imagined one [10]. Collaborative Virtual Reality Environments (CVRE) extends the VR definition since CVREs are used for collaboration and interaction of possibly many participants that may be spread over large distances. The applications are usually based on the shared virtual environment [11]. CVREs can be accessed through the Internet and allows a group of geographically separated users to interact in real time. Collaboration and Knowledge Management in Virtual Reality is subject of active and continuing research $[12,13,14]$.

Among the platforms available to develop Knowledge Management in a CVRE is Second Life ${ }^{\mathrm{TM}}$ which is a virtual 3-dimensional world where the participants have the ability to develop and share multimedia content using a very simple user graphic user interface. Second Life is a commercial enterprise with 14 million users worldwide. An example of Second Life ${ }^{\mathrm{TM}}$ knowledge management environment for plant shutdown planning is the Binary Distillation rig shown in Fig. 2, which is modeled on facilities at the Chevron Pascagoula refinery the largest refinery in the United States shown in Fig. 3.

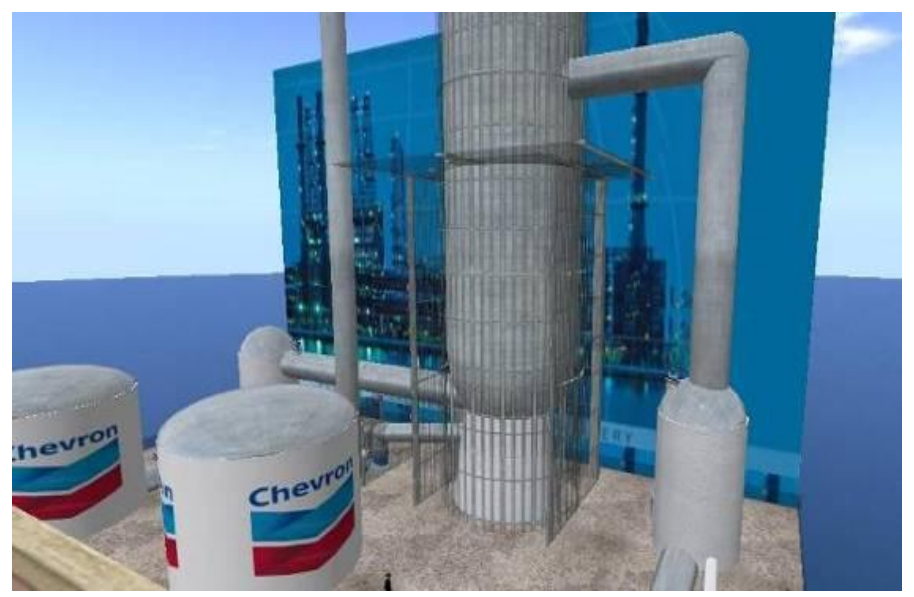

Fig. 2. A binary-distillation rig, which is modeled on one of the 46 complex industrial machines at the Chevron-Pascagoula plant.

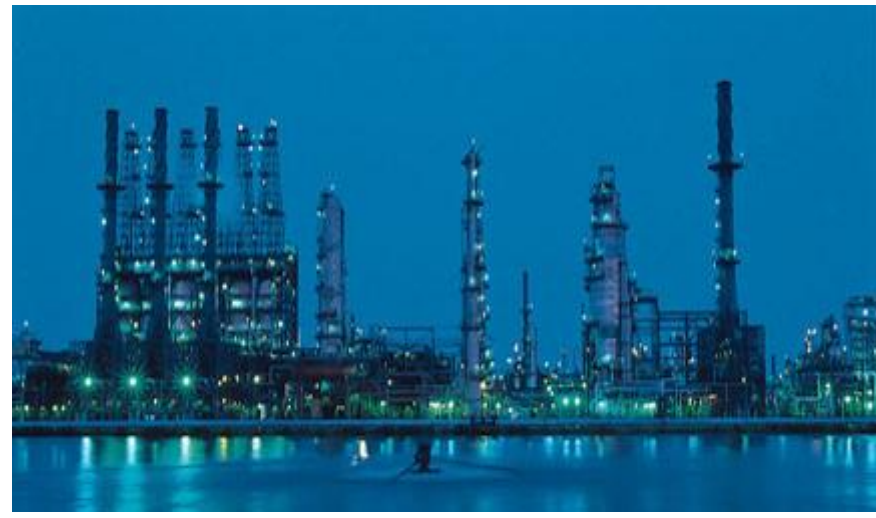

Fig. 3. The Chevron refinery in Pascagoula Mississippi - the largest in the United States.

The purpose of the CVRE virtual refinery process rig is to facilitate knowledge management in preparation for plant shutdowns essentially for all participating contractors, consultants and operators to agree on the sequence and timing of necessary operations to be performed during shutdown. One of the challenges of using CVRE for Knowledge Management is the integration of dynamic 2-dimensional (graphics and text) content more traditionally created during a discussion among stakeholders of a plant shutdown and the 3-dimensional objects in the environment. Therefore, the research team has developed and integrated a Collaborative Virtual Whiteboard (CVW) into the virtual refinery environment.

\section{THE COLLABORATIVE VIRTUAL WHITEBOARD}

The CVW is built upon and takes advantage of "Twiddla" which is a web-based whiteboard technology that allows stakeholders to share a document and collaboratively make modification to the document. These changes are shown to all the participants in real-time through an Internet connection [15].

CVW is fundamentally a bridge into and out of the CVRE as shown in Fig. 4. The whiteboard screen is connected through the virtual media settings to a dedicated twiddla workspace.

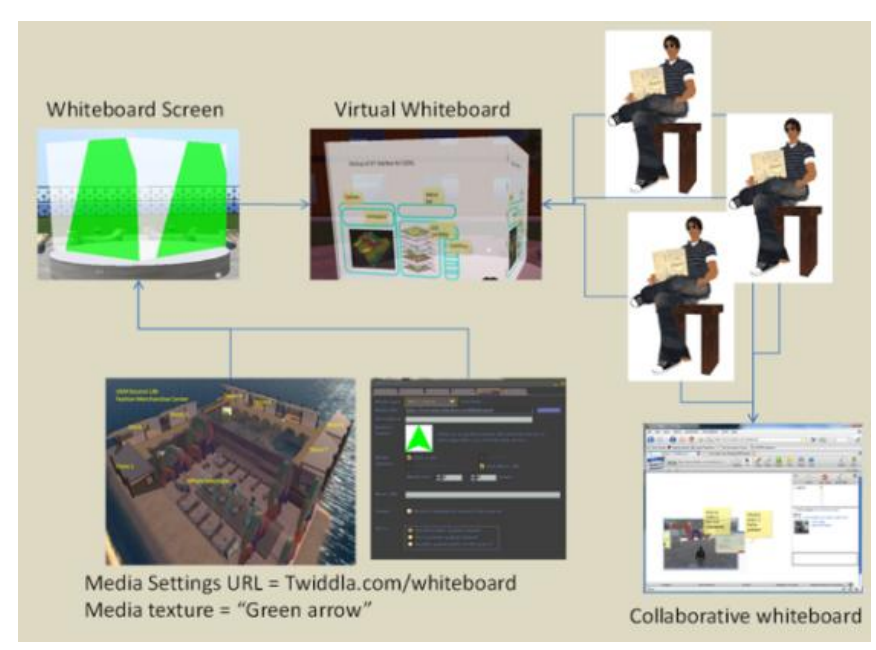

Fig. 4a. Structure of the Collaborative Virtual Reality Whiteboard. 
This workspace is reachable by anyone who clicks on the rotating semi-translucent whiteboard screen inside the CVRE. Stakeholders can then see what each participant has drawn, written, or uploaded as shown in Figure 4b.

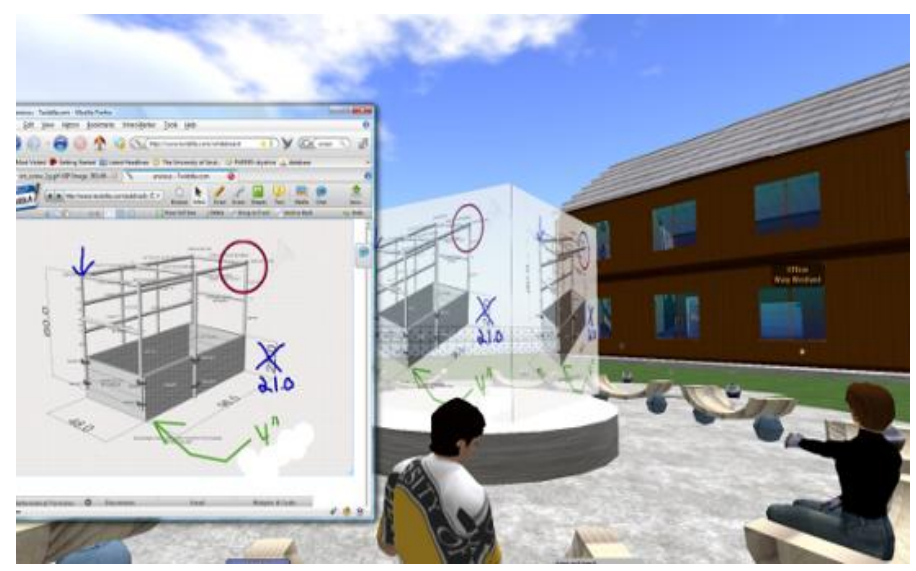

Fig. 4b. Clicking on the virtual display brings up a collaborative contribution window that allows all participants to both see and edit shared 2-dimensional images and documents within the 3-dimensional environment.

The embedded Twiddla workspace can take all participants to any web page which can then be collaborative annotated and can upload various document formats including Microsoft Word and PowerPoint and Adobe PDF. These documents can then be annotated and images of the session can be saved by any participant as shown in Fig. 5.

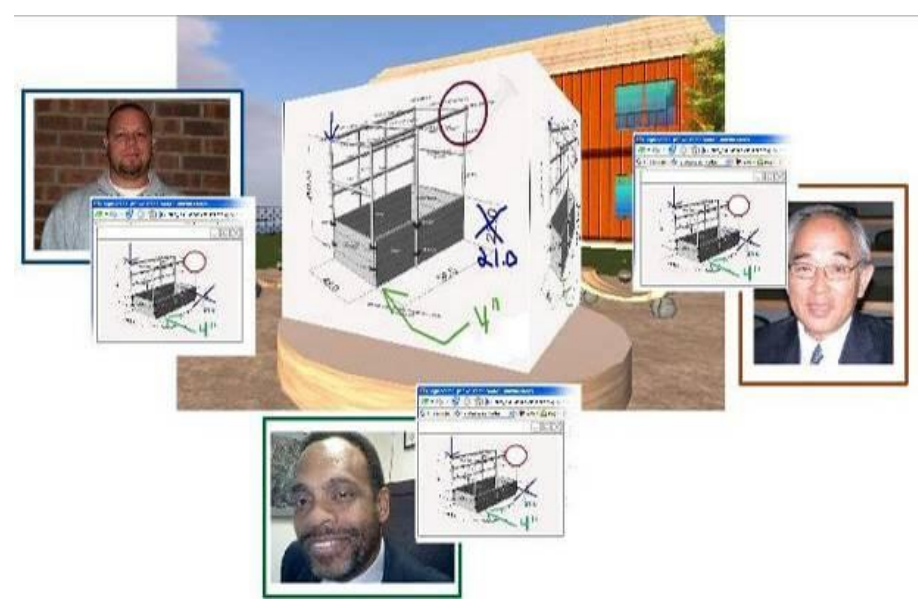

Fig. 5. Collaborative design and planning using the Collaborative Virtual Whiteboard in Virtual Reality.

This new avenue for communication opened by CVW technology is already being used for collaborative design as shown in Figures $4 \mathrm{~b}, 5$ and 6 facilitating communication between U.S. Army Corps of Engineer scientists and University of Southern Mississippi Computer Science faculty and students.

The ultimate goal of gathering, clarifying and managing knowledge through CVW technology is the realization in the Virtual Environment of a three-dimensional object with an associated action plan that encapsulates the combined knowledge and experience of all stakeholders. The collaborative environment allows participants to act together to edit the environment and add a new set of 3D objects which represent the sum of ideas and understanding developed in the CVW session. This 3D object scripted with behaviors and notations then becomes the centerpiece of planning and training for plant shutdown. Fig. 6 shows an early exercise for the construction industry in Collaborative Knowledge Clarification resulting in an object that represents a "meeting of the minds" despite geographic distance of the participants.

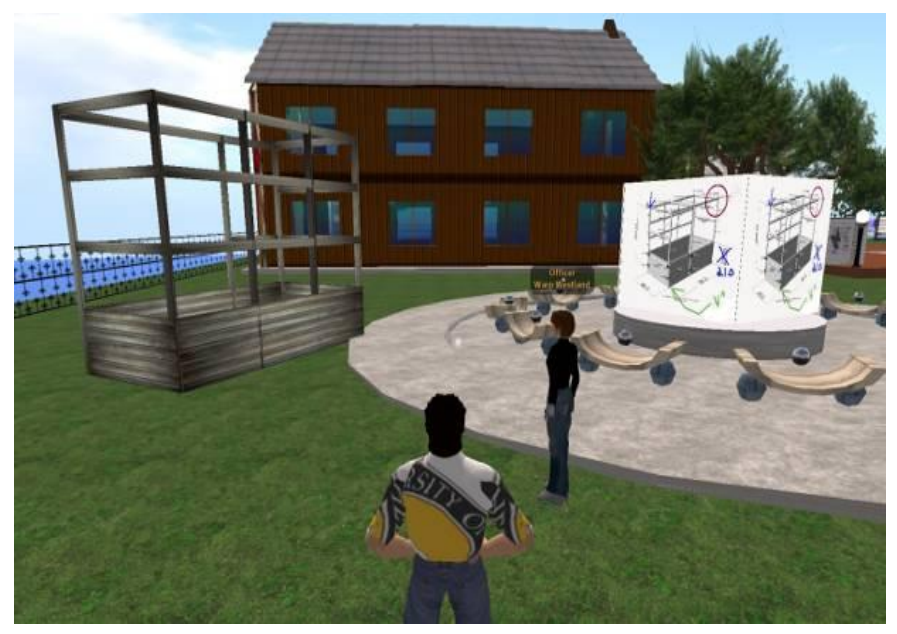

Fig. 6. The end result of collaborative planning - a realized and scripted Virtual Object which represents the collective understanding of a real world problem.

Based on the construction industry experience, the project team is actively building a knowledge capture center for refinery shutdown based on preliminary schematics provided by long time industry consultants. This first attempt is a 40 -foot basic binary distillation rig that provides an experimental laboratory for knowledge transfer and correlation as well opportunities to enhance the scripted behavior of which enhances understanding of fundamental operation and shutdown. Fig. 7 shows transfer of knowledge from a Piping and Instrumentation Diagram (PID) and local knowledge to research personnel engaged in scripting of boiler input and cleaning operations using CVW.

In a small scale experiment two graduate computer science students were assigned the task of implementing the behavior of a binary distillation rig with the help of an industry consultant. The first "control" student was asked to use only paper and pencil in gathering her understanding of the functionality of the refinery element. Fig. 7 shows the control student's notes from her 2 hour meeting with the consultant. This jumble of ideas is a good example of the difficulty of capturing knowledge about the functionality of complex 3-dimensional objects across subject disciplines.

The control student was unable to make effective use of the knowledge she had attempted to capture and abandoned the project after approximately 50 hours of fruitless struggle.

The second "CVRE student" used the basic binary distillation rig built in Second Life ${ }^{\mathrm{TM}}$ and multiple CVW whiteboards to capture the knowledge of the consultant. As shown in Fig. 8 the focus of the 2 hour meeting was the use of the collaborative whiteboards to gather and catalog knowledge. 


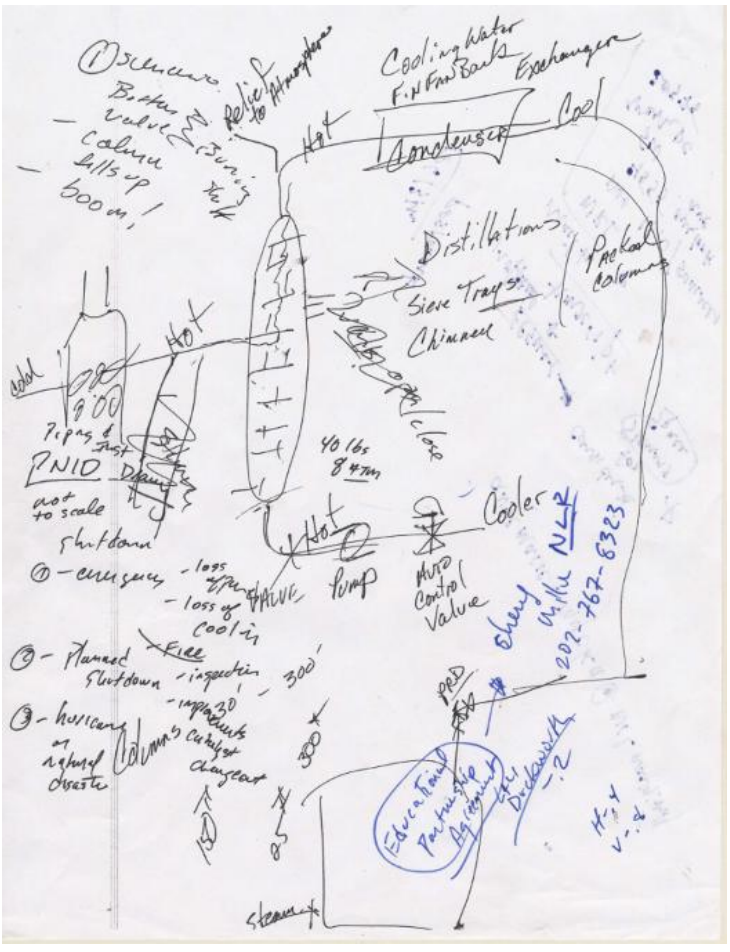

Fig. 7. Knowledge management notes from a student who interviewed a consultant with only paper and pencil.

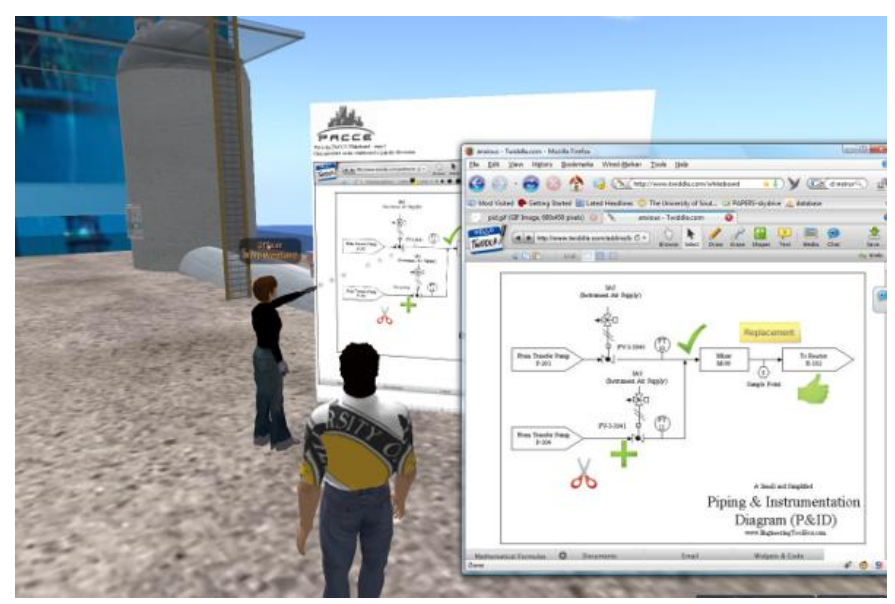

Fig. 8. Use of Collaborative Virtual Whiteboards to capture knowledge about a the behavior and operation of a basic binary distillation rig.

Using the whiteboards as a guide the CVRE student completed a first version of the desired refinery equipment in about 100 hours with 42 of the 64 event states correct on the first try. Fig. 9 shows the resulting scripted refinery behavior (in this case incorrect operation has led to a fire).

Many refinery units are either identical or similar to other installation elsewhere in the world and knowledge management in preparation for plant shutdown is particularly desirable in cases where similar operation have taken place elsewhere. However, knowledge management across international boundaries is made more difficult by language and cultural boundaries. Early experiment in international knowledge transfer has been very promising including an unexpected benefit of facilitating annotation of diagrams in native script that do not use western characters. Fig. 10 shows an experiment

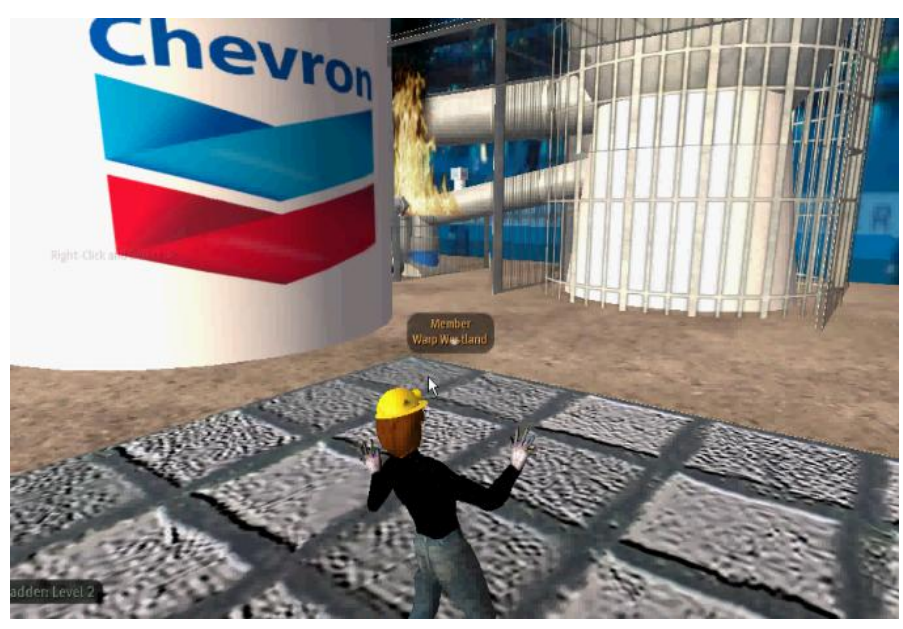

Fig. 9. CVRE Binary Distillation Rig showing incorrect operation leading to a fire.

with Mandarin speakers who are able (for the first time) to use a collaborative CAD-like environment in real-time with embedded communication in their native idiom.

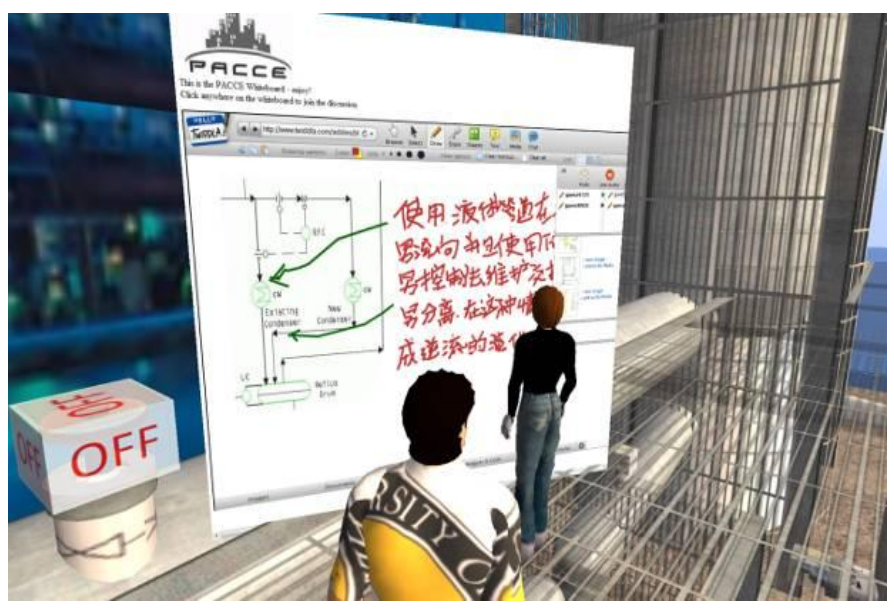

Fig. 10. Experiment in cross-cultural communication using Collaborative Virtual Whiteboard embedded in the virtual refinery installation.

The immediate success of the Collaborative Virtual Whiteboard has encourages a wide experimentation with embedding various web-based tools inside Second Life.

\section{EMBEDDING COLLABORATIVE WEB APPLICATIONS IN SECOND LIFE}

Any web page may be displayed in Second Life ${ }^{\mathrm{TM}}$ by building an object which matches a regions media texture and setting the media URL to the desired location. Flash ${ }^{\mathrm{TM}}$ is not currently supported by Second Life ${ }^{\mathrm{TM}}$ but a variety of other technologies including Java and the Google Web Toolkit ${ }^{\mathrm{TM}}$ (GWT) work very well. Figure 11 shows "MindMeister" [16] an interesting and potential useful GWT-based brainstorming tool embedded in Second Life ${ }^{\mathrm{TM}}$. 


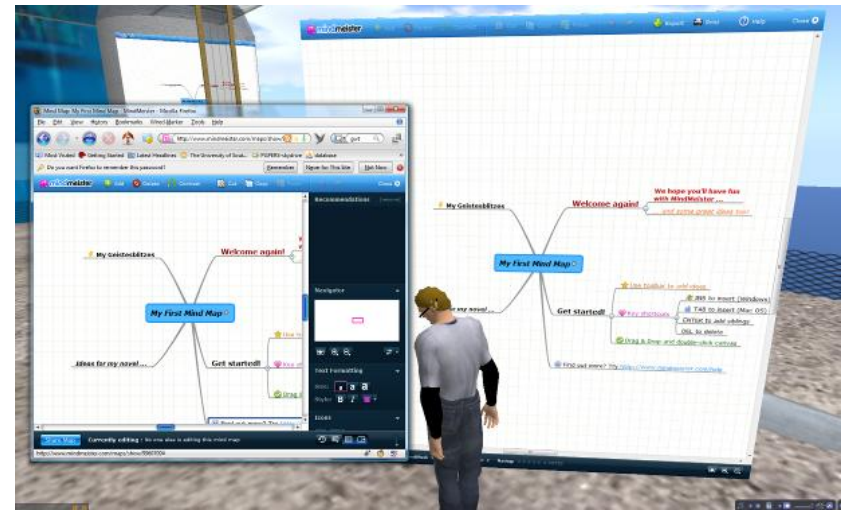

Fig. 11. MindMeister a collaborative GWT-based brainstorming tool embedded in the Second Life ${ }^{\mathrm{TM}}$ environment - reachable by all region residents by clicking on the display and using the pop-up browser.

The display on a virtual texture is not interactive. Thus, a collaborative web-based application must be reachable without a login (or through a general HTTP POST login). A simple Second Life script can then be added to the display which will take multiple users to the same public collaborative tool where they can then all add their own contributions which can be viewed by all in the virtual environment,

\section{CURRENT WORK}

Current work is focused in two areas:

1. Expanding the number of collaborative tools that provide unusual pathways for sharing and utilizing knowledge in the Virtual Environment.

2. Development and movement from proprietary and remote Second Life ${ }^{\mathrm{TM}}$ to open source and local hosted OS-BEST a branch off RealXtend [17] and Opensim [18] under development by the Construction/Computing group at USM.

\subsection{Collaborative Tools}

Figure 12 shows a recently developed interactive heads-up display (HUD) developed in collaboration with The University of Southern Mississippi School of Psychology. The collaborative aspect here is that the interactive menu of choices, in this case for an Alcohol Relapse resistance experience, is driven by an external database. By giving psychology researchers access and minimal training in the database model underlying the HUD it is then possible for them to work in the environment on new and revised virtual experiences without low-level programming experience. Fundamentally, they are able to share knowledge among themselves and deliver the sum of their knowledge to their research subjects without the filter of non-psychologist programmers

The team is also particularly interested in embedding more effective knowledge-sharing programming tools such as the "UNA" real-time collaborative programming environment [19]. Collaborative scripting in Second Life ${ }^{\mathrm{TM}}$ consists of repeatedly handing control of a jointly developed object back and forth, a tedious and error-prone development pattern. Real time collaboration on Virtual scripting would be an enormously helpful on large development projects. Fig. 13 shows a mockup of a collaborative programming environment embedded in Second Life ${ }^{\mathrm{TM}}$ that would allow programmers to share control of a virtual object and see the changes that all collaborators were making in real time.

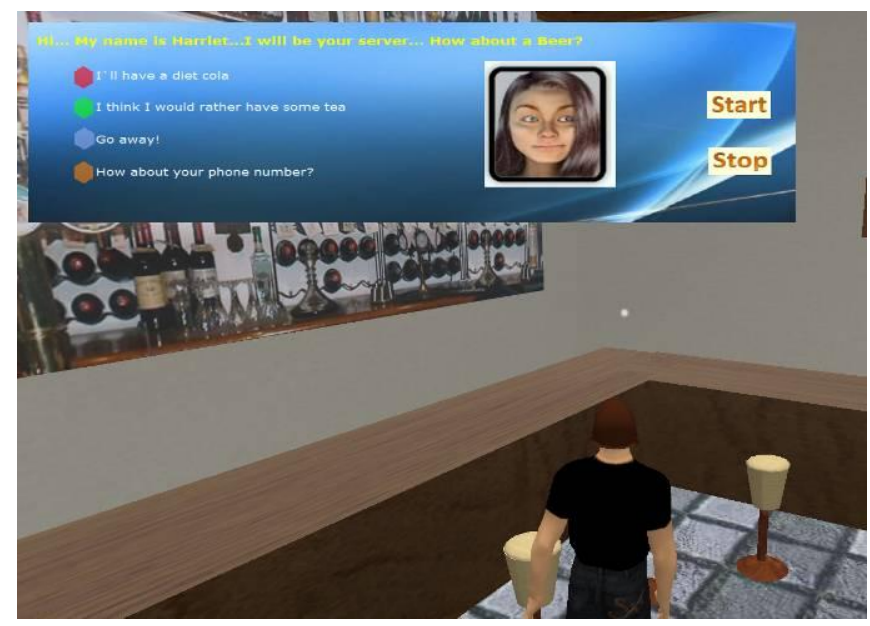

Fig. 12. A database-driven virtual experience that allows psychology researchers to collaboratively and iteratively develop new experiences without the aid or interference of programmers.

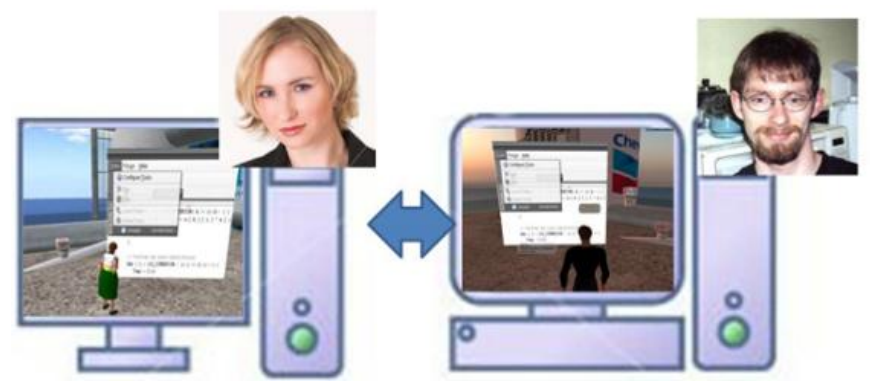

Fig. 13. Collaborative Programming in Virtual Reality using an embedded Real Time Collaborative Integrated Development Environment.

\subsection{OS-BEST}

Opensim [18] began as a project to reverse engineer or work backwards from the open source Second Life ${ }^{\mathrm{TM}}$ viewer to the still closed source Second Life ${ }^{\mathrm{TM}}$ server. The capabilities of Opensim have progressed very rapidly and the focus has shifted from duplicating the features of Second LifeTM to the development of new features. One such project is RealXTend [17] which add Open Graphics Engine (OGRE) [20] functionality to Opensim. The addition of OGRE shading and rendering is particularly useful for the development of construction and heavy industry simulation. An example which is a mockup of the new container port under development in Gulf Port Mississippi is shown in Fig. 14.

The move towards an open source solution is motivated by the need for security as prototype environments move towards actual field use but the ability to add new functionality was also an important consideration. OS-BEST is a set of additional capabilities built on top of RealXTend which is itself a branch off of Opensim. Current OS-BEST modules under development are as follows: 


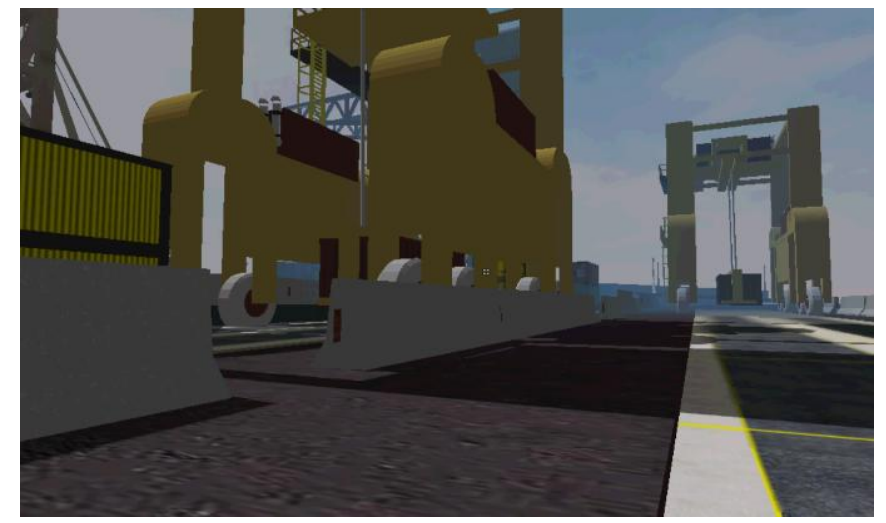

Fig. 14. Virtual Mockup in OS-BEST showing RealXtend shading and rendering of the container port under development at Gulf Port Mississippi.

Security: A CVRE version which runs on a local server and uses secure SSH for communication.

1. LabView: A bridge to the widely used LabView [21] virtual instrumentation library which allows easy connectivity between the virtual environment and remote virtual instrument panels or actual instrument hardware. An example of a LabView instrumentation in OS-BEST is shown in Fig. 15.

2. Python Socket: An efficient communication layer to facilitate network programming connecting the virtual environment with external drivers or data sources.

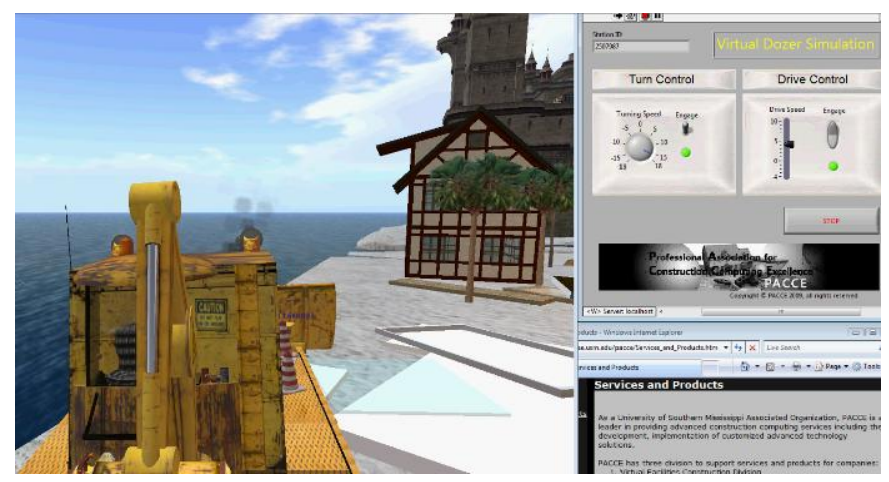

Fig. 15. Bulldozer simulator built in OS-BEST with connection to LabView remote controller interface.

These new capabilities will dramatically improve the ability of engineers to communicate, collaborate and manage knowledge in CVRE virtual workplaces.

\section{REFERENCES}

[1] Goode R. Gestión del Conocimiento. http://www.masternewmedia.org/es/gestion_del_conocimiento.htm, 2008

[2] M. Alavi and D. Leidner Knowledge management systems: issues, challenges, and benefits. Communications of the AIS, Volume 1, Issue 2es, 1999. http://portal.acm.org/citation.cfm?id=37411

[3] R. Addicott, G. McGivern, E. Ferlie. Networks, Organizational Learning and Knowledge Management: NHS Cancer Networks Public Money \& Management, Vol. 26, No. 2, pp. 87-94, April 2006. http://papers.ssrn.com/sol3/papers.cfm?abstract_id=889992.

[4] R. McAdam, S.A. McCreedy Critique of Knowledge Management: Using A Social Constructionist Model. New Technology, Work and
Employment, Vol. 15, \#2, 2000.

http://papers.ssrn.com/sol3/papers.cfm?abstract_id=239247.

[5] M. Thompson, G. Walsham. Placing Knowledge Management in Context. Journal of Management Studies, Vol. 41, No. 5, pp. 725-747, July 2004. http://papers.ssrn.com/sol3/papers.cfm?abstract_id=559300

[6] L. Amendola. Tips for the Management of Plant Maintenance Saves - "Turnaround - Shutdowns Management". Mantenimiento Mundial, 2008.

http://www.mantenimientomundial.com/sites/mmnew/bib/notas/pa radas.pdf

[7] H. Sjøvoll and E. Tjåland. Immersive Safety Handling and Training. Computational methods in science and technology, Special Issue 2006, 55-60.

[8] SYDAC. Full Immersion Training Simulations. 2009. http://www.sydac.com.au/index.php?option=com_content\&task=v iew\&id $=84 \&$ Itemid $=63$.

[9] E.MATION. InterSense: Industrial Case Studies, 2009. http://emationtech.com/Solutions/Technologyunit/Hardware/InterS ense/InterSenseIndustrialCaseStudies.aspx.

[10] F. Theoktisto, On Extending Collaboration in Virtual Reality Environments. proc. of XVII Brazilian Symposium on SIBGRAPI 2004.

[11] C. Bouras and F. Filopoulos (1998) Distributed Virtual Reality Environments Over Web for Distance Education, 1998. ru6.cti.gr/Publications/269.pdf.

[12] L. Pugnetti, L. Mendozzi, E. Barbieri, D. Alpini, EA. Attree, BM. Brooks, FD. Rose (1998) A. Motta, Developments of collaborative research on VR applications for mental health. Focus on Cybersickness and memory testing, International Journal of Virtual Reality, 4(1): pages 39-45.

[13] D. Bowman, J. Chen, C. Wingrave, J. Lucas, A. Ray, N. Polys, Q. Li, Y. Haciahmetoglu, J. Kim, S. Kim, R. Boehringer, T. Ni (2008) New Directions in 3D User Interfaces, International Journal of Virtual Reality, 5(2): pages 3-14.

[14] A. García, J. Molina, D. Martínez and P. González, Enhancing Collaborative Manipulation Through the Use of Feedback and Awareness in CVEs (2009) International Journal of Virtual Reality, 8(2):pages $45-50$.

[15] TwIDDLA. Twiddla - A Collaborative Web-based Whiteboard System, 2009. www.twiddla.com

[16] MindMeister. A Collaborative Brainstorming Web-Based Tool, 2009. www.mindmeister.com.

[17] RealXTend. RealXtend Open Platform for Interconnected Worlds. 2009 www.realxtend.com.

[18] Opensim. Open Virtual Simulator. www.opnesim.org.

[19] N-BRAIN. UNA collaborative Real Time Programming, Environment, 2009. www.n-brain.net.

[20] OGRE. Open Source Graphics Engine. www.ogre3d.org.

[21] Labview. Virtual Instrumentation Builder. 2009 National Instruments.

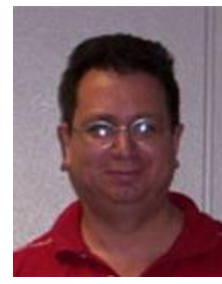

Andrew Strelzoff is Computer Science Coordinator and Assistant Professor of Computer Science at the University of Southern Mississippi. He has 8 years of industrial experience as technical lead for Ayres Group (a major residential construction company in Southern California). He received his Ph.D. from the University of California - Santa Barbara (2004) in Computer Science. His research is focused on Process Engineering and the facilitation of interdisciplinary work in Virtual Reality.

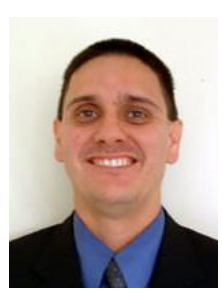

Tulio Sulbaran is an Associate Professor at the University of Southern Mississippi's School of Construction and is the director of the Innovation for Construction and Engineering Enhancement (ICEE) center. He received his BS in Civil Engineering from the University Rafael Urdaneta in Venezuela and his Ph.D in Civil Engineering from the Georgia Institute of Technology. His research interest is on the impact of information technology resources on construction and engineering education and training. 